\title{
A study of Facebook use among undergraduate students in Jordan
}

Shaidah Jusoh*, Hejab M. Al Fawareh

Faculty of Computing and IT, Northern Border University, Rafha, Saudi Arabia

\section{ART ICLE INFO}

\section{Article history:}

Received 4 November 2016

Received in revised form

4 March 2017

Accepted 6 March 2017

\section{Keywords:}

Behaviors

Facebook

Arab world

Gender differences

\begin{abstract}
A B S T R A C T
The purpose of this study is to explore behaviors of Facebook users at an undergraduate level in Jordan. We have conducted a survey using questionnaires. The questionnaires were distributed to 200 undergraduate students who enrolled in computer science, information systems, internet technology and software engineering programs. Out of 200, 180 valid responses had been returned; $88 \%$ of the respondents have a Facebook account. This study has revealed that although Facebook can be displayed in the Arabic language, 64\% of users use Facebook in the English language. Gender differences also show effects on Facebook usage. Male users are more daring than female users in posting personal information such as photos, phone numbers, and addresses. These findings also suggest that female users in Jordan are more conservative than male users when they appear online. However, there were no significant differences between genders when it comes to the political discussions. For both genders, a "friends" factor is the most incentive to have a Facebook account. Finally, this study suggests that the main reason for students in the Arab world to have a Facebook account is to stay connected and chat with friends.
\end{abstract}

(C) 2017 The Authors. Published by IASE. This is an open access article under the CC BY-NC-ND license (http://creativecommons.org/licenses/by-nc-nd/4.0/).

\section{Introduction}

The Internet has become a very popular and powerful medium in this decade. It has affected almost every aspect of people routine on a daily basis. It has even changed many people's lifestyles. Some of the biggest Internet effects involve intercommunications between people around the world. The Internet has made something impossible become possible. A few years back, people were able to communicate, and send messages online regardless a location; the power of the internet enabled only 2 persons who are thousands of miles away to communicate and be in touch in a real time. Nowadays, with an invention of social networking sites (SNSs), communication is not only based on one to one, but also one to many, and many to one. SNSs are now often used for communications, to build relationships, and to make new friends.

The SN websites have been built on the concept of human connections, allowing people to connect from all over the world. Examples of SN websites are Twitter, Facebook, MySpace, Friendster, Google+ and Badoo. One of the biggest advantages of these

\footnotetext{
* Corresponding Author.

Email Address: shaidah.jusoh@nbu.edu.sa (S. Jusoh) https://doi.org/10.21833/ijaas.2017.04.009

2313-626X/C 2017 The Authors. Published by IASE. This is an open access article under the CC BY-NC-ND license (http://creativecommons.org/licenses/by-nc-nd/4.0/)
}

websites is that they are extremely easy to use with little knowledge about computers and how the Internet works. The SNSs offer a new way to understand, connect with, and learn information about other people. The websites have been used for different kind of purposes including politics, marketing, education, and so on. The current generation of young people has grown up with access to computers and the Internet, and thus, may appear to have a natural ability and high skill levels when using new technologies.

Facebook was originally created by a college student for college students. Now, however, it has been widely used by all types of people. Facebook had around 1.2 million active users in 2006, and as of the third quarter of 2016, Facebook had 1.79 billion monthly active users. With the increase of mobile devices on market such as smartphones, the number of mobile users has also increased.

Facebook has become the touchstone for how non-profit organizations, environmental activities, and political factions reach out to thousands of potential volunteers and donors. On the other hand, Twitter has been also used by almost all progressive politicians to promote their causes, and express their opinions on many current issues. Students frequently have computers and internet access in their houses, dormitories, and schools (Ahn, 2011) and when they have access to the Internet at a friend's or family member's house, this increases the 
likelihood of their use of both Facebook and MySpace (Hargittai, 2007). They spend a large portion of their daily life on the Internet, for socializing through social networks like Facebook. Research results also indicate that Facebook users are predominantly students, especially university students (Pempek et al., 2009; Vrocharidou and Efthymiou, 2012; Aydin, 2012).

The total number of Facebook users in the Arab world as of the end of May 2013 is 54,552,875 up from 45,194,452 in June 2012. The Jordan Times also reported that Facebook penetration in Jordan has reached $41.4 \%$ by the end of March 2013, with about 2.653 million users. The majority of Facebook users in the Arab world are mostly students in the range between 13 to 24 years old (55\%), while Facebook users in the West for the same age group represents only about $36 \%$, and the majority of them lies in range between 25 to 60 years old and older, and mostly are outside of college (Yaseen and $\mathrm{Al}$ Omoush, 2012). On the other hands, Akour et al. (2006) claimed that the Jordanians have a negative attitude towards social impacts of the Internet. The Jordanians did not want it to replace their traditions, values, customs of interactions, and caring. However, this result had been disapproved by the study conducted by Bsharah et al. (2014).

The aim of this study is to determine behaviors of Facebook users who are also undergraduate students in Jordan. This paper is organized as follows, Section 2 presents the previous research work, and Section 3 presents research questions and methods. Data analysis, results, and discussions are presented in Section 4. Section 5 concludes the paper.

\section{Literature review}

Nearly $67.4 \%$ of internet users worldwide use a social network in 2016, and Facebook still remains the largest social network. A research community in this area has conducted a number of studies related to Facebook, focusing on several issues of Facebook usage, including reasons why people use Facebook, privacy, behavior differences between genders, positive and negative impacts of Facebook, Facebook in education, and so on.

Hull et al. (2011) conducted a study on privacy issues. Their study pointed out that, while online friendship may be derived from offline notions of social relationships, online friends are clearly different from offline friends. Although, users appear largely to use the site to strengthen and reinforce offline social ties, however, it is quite easy to "friend" someone, and Facebook users often have vast numbers of casual friends. Despite many cases or warnings and well-publicised career, relationships or friendships-damaging incidents, Facebook users continue to post vast amounts information about themselves.

There are also several studies that have been conducted to explore Facebook usage mainly among students in various regions. For example, Benson et al. (2010) have examined the use of SNS among business students in the United Kingdom. In their study, they found key differences among undergraduate and postgraduate students in terms of gender, program, and age. Their study addressed that undergraduate students use Facebook mainly to keep in touch with friends while postgraduate students use Facebook for general socializing. AlSharqi et al. (2015) reported undergraduate students at the King Abdulaziz University (KAU) in Saudi Arabia use Facebook to be connected with other students.

In order to understand the gender differences in Facebook usage among United Arab Emirate (UAE) college's students, Shen and Khalifa (2010) conducted a survey in a private university in the UAE during the 2008 spring semester. They mainly focused on the following subjects: self-perception in Facebook; frequent activities with Facebook; perceived consequences; subjective norms; and overall attitude to using Facebook. Their findings showed that Facebook seemed more important for female students to extend their social networks, get information, and experiment with different identities.

The effects of Facebook usage on undergraduate students have been also studied. According to Karpinski and Duberstein (2009), an extended presence on Facebook can negatively effect on productivity and task performance. Rouis et al. (2011) had investigated effects of Facebook usage on undergraduate students at the Lulea University of Technology in Sweden. They found out that extensive use of Facebook led to poor academic performance.

Some studies had been also conducted to determine the use of Facebook for class activities, to support learning and teaching. Eren (2012) conducted a study to investigate students' attitude towards the use of Facebook in foreign language classes in a university in Turkey. For the purpose of the study, Facebook was used to support language learning activities for one semester long. The results of the study showed that the students had a positive attitude towards the use of Facebook as a supplementary tool to support their learning, where the students believed that the use of Facebook would improve their language skills, and the use of Facebook was effective in supporting their learning compared to traditional face-to-face settings.

\section{Material and method}

Survey questionnaires were distributed to 200 undergraduate students at one of the private universities, in Jordan. Selected participants enrolled in computer science, information systems and internet technology and software engineering programs. No honorarium was offered.

The questionnaire was constructed by researchers of this study. Questions were derived from previous literature. Each questionnaire consists of 2 parts. The first part consists of questions related 
to demographic data such as gender, age group, hometown and a question whether she/he owns a Facebook account or not. The second part consists of questions which focus on the usage of Facebook. The following research questions have been constructed to serve the purpose:

-Q1: Is having an internet connection at home can facilitate for having a Facebook account?

-Q2: Are most Facebook users aware of privacy issues?

-Q3: Do female Facebook users show more concern about the privacy issue?

-Q4: Does Facebook supports peer learning?

-Q5: Do students discuss personal issues on Facebook?

-Q6: Do students use Facebook as a means for political discussions?

-Q7: Is there any relationship between age and gender in discussing political issues?

-Q8: What is the main activity on Facebook?

-Q9: Which language do students use on Facebook?

The total of 180 participants returned a valid response, 124 males, and 56 females. Out of 180 respondents, $88 \%$ have answered 'yes' to the question "do you have an account on Facebook?". The smaller number of female participants in this study is affected by the number of students who enrolled in the programs. Students' age is in the range 16-30 years old. Fig. 1 demonstrates the distribution of participants according to their age group, where the majority of participants are in the range between 19 to 25 years old. Participants who are in the age group of 26-30 years old are normally mature students or part-time students.

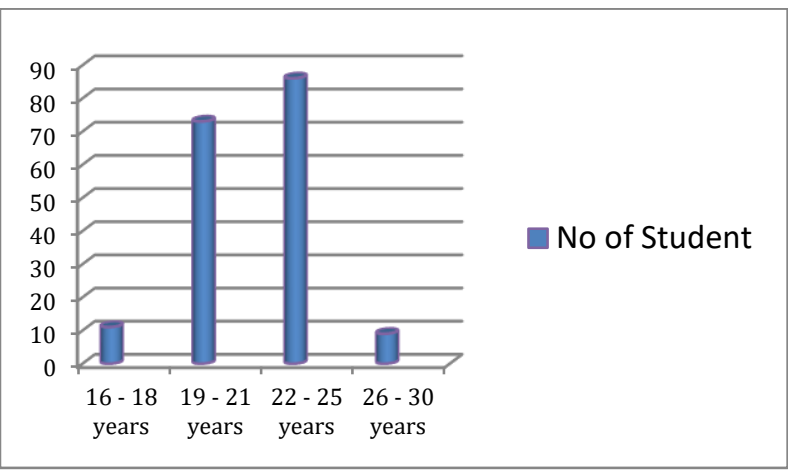

Fig. 1: The number of participants according to age group

\section{Results and discussion}

In order to assess what has facilitated students to have a Facebook account (Q1), a logistic regression model was used. The categorical response variable was having a Facebook account (coded as Yes=1, No $=0$ ), while having an internet connection at home was the categorical predictor while adjusting for demographic variables gender, age, and social, variable incentives for having a Facebook account. The results of this model are presented in Table 1 . Students who had an internet connection at home $(\beta=2.4677, p<0.001)$ were more likely to have an account on Facebook (Q1), while adjusting for gender, age and incentives. Age or gender did not have any significant effect on having a Facebook account $(\mathrm{p}>0.05)$. Friends' incentive was a highly significant factor influencing students to have a Facebook account.

Table 1: Regression model for factors influencing possession of a Facebook account

\begin{tabular}{cccc}
\multicolumn{4}{c}{ possession of a Facebook account } \\
\hline & Coefficients & $\mathrm{z}$ & $\mathrm{p}$-value \\
\cline { 2 - 4 } Intercept & -3.1358 & -1.675 & 0.093879 \\
Internet(Yes) & 2.4677 & 3.281 & 0.001036 \\
Gender (Male) & 0.5454 & 0.856 & 0.391927 \\
Age (19-21) & 2.1071 & 1.145 & 0.252058 \\
Age (22-25) & 1.2129 & 0.665 & 0.506278 \\
Age (26-30) & 1.0715 & 0.516 & 0.605875 \\
Incentive (family) & 1.5439 & 1.800 & 0.071825 \\
Incentive (friends) & 4.3209 & 3.798 & 0.000146 \\
\hline
\end{tabular}

In this study, Facebook users were asked whether they post their personal information such as photos, phone numbers, and addresses (Table 2). More than $60 \%$ of the users were disclosing personal information like posting photos and addresses, but only $40 \%$ of the users post their phone numbers. A comparison between genders for posting photos, $82 \%$ of Facebook male users post photos on Facebook, the corresponding percentage from the female group was $36 \%$. The proportion of male users $(82 \%)$ posting photos on Facebook was significantly different from female users, $\chi^{2}$ p-value $<0.001$.

Table 2: Posting personal information

\begin{tabular}{ccc}
\hline Question & \multicolumn{2}{c}{ Response } \\
\cline { 2 - 3 } Do you post your photos on & Yes & No \\
$\begin{array}{c}\text { Facebook.com } \\
\text { Do you post your phone number } \\
\text { on Facebook.com }\end{array}$ & $69.56 \%$ & $30.44 \%$ \\
$\begin{array}{c}\text { Do you post your address on } \\
\text { Facebook.com? }\end{array}$ & $40.37 \%$ & $59.63 \%$ \\
\hline
\end{tabular}

Data analysis reveals that almost $60 \%$ of Facebook users were aware of privacy issues as shown in Table 3 (Q2).

Table 3: Privacy awareness

\begin{tabular}{ccc}
\hline \multirow{2}{*}{ Question } & \multicolumn{2}{c}{ Response } \\
\cline { 2 - 3 } $\begin{array}{c}\text { Do you aware of the privacy } \\
\text { issues on Facebook }\end{array}$ & Yes & No \\
\hline
\end{tabular}

Evidently, there were gender differences in the awareness of privacy issues, where $61 \%$ of male users were aware of privacy issues on Facebook, while only $49 \%$ female users were aware of such problems. Gender differences in Facebook usage among female and male students suggests that that male users are more aware of privacy issues more than female users (Q3). However, the percentage of male users posting their personal information such as phone numbers, addresses, and photos is higher than female users. This contradiction may suggest that female users are more worries to display their personal information on public and are more conservative when they appear online. This attitude 
might be influenced by the local culture. This finding clarifies the claim made by Akour et al. (2006).

To explore whether Facebook users understand how to keep their privacy, a question of how they publicized their profile was asked. The respondents were supposed to select private, public or customize. Data analysis shows that $48 \%$ of respondents kept their profile as private. The percentage of respondents is recorded as in Table 4.

Table 4: Ways of publicizing user profile

\begin{tabular}{cccc}
\hline \multirow{2}{*}{$\begin{array}{c}\text { Question } \\
\text { How do you }\end{array}$} & Private & Public & Customize \\
\cline { 2 - 4 } $\begin{array}{c}\text { publicize your } \\
\text { profile }\end{array}$ & $48 \%$ & $35 \%$ & $17 \%$ \\
\hline
\end{tabular}

To determine the main purpose of having a Facebook account, users were asked to choose only one from listed activities; messaging, chatting, and writing the wall (Table 5). The majority of students use Facebook for a chatting (Q8) purpose. Furthermore, more than $70 \%$ of Facebook users chat about their personal life issues on Facebook (Q5).

This study also reveals that more than $70 \%$ of the users in the age groups 19-25 discuss political issues on Facebook (Q6). The percentage of users discussing political issues was almost the same across the 2 groups of gender (Q7). Table 6 shows gender by political discussion classification among the Facebook users. A $\chi 2$ test of association was used to test if political discussions are independent of gender. The results of $\chi 2$ test reveal that there was no association between gender and political discussions on Facebook, $\chi 2$ p-value $=0.8876$.

A similar $\chi^{2}$ test was performed for the crossclassified data in Table 7 . The interest in political discussions on Facebook was independent of age, $\chi^{2}$ $\mathrm{p}$-value $=0.3991$. Thus, we conclude that there is no significant association between age groups and the interest in political discussions on Facebook.

Table 5: Activities on the Facebook

\begin{tabular}{cccc}
\hline \multirow{2}{*}{ Question } & \multicolumn{3}{c}{ Response } \\
\cline { 2 - 4 } What is your major activity on the Facebook & Messaging & Chatting & Writing on the Wall \\
& $24 \%$ & $46 \%$ & $30 \%$ \\
\hline
\end{tabular}

Table 6: $2 \times 2$ Contingency table showing frequency of Facebook users classified by gender and political discussion on

\begin{tabular}{cccc}
\multicolumn{4}{c}{ Facebook } \\
\hline Gender & Politics (Never) & Politics(Yes/Always/ sometimes) & Total \\
\hline \multirow{2}{*}{ Female } & $11(25 \%)$ & 32 & 43 \\
& & $(75 \%)$ & 113 \\
Male & $32(28 \%)$ & 81 & 156 \\
Total & 43 & 113 & $15 \%$ \\
\hline
\end{tabular}

Table 7: $4 \times 2$ Contingency Table showing frequency of Facebook users classified by age groups and politics discussion on Facebook

\begin{tabular}{cccc}
\hline Age & Politics (Never) & Politics(Yes/Always/sometimes) & Total \\
\hline Group 1 (17-21) & 17 & 55 & 72 \\
Group 2 (22-30) & 26 & 58 & 84 \\
Total & 43 & 113 & 156 \\
\hline
\end{tabular}

A second logistic regression model was fit for the Facebook users' data with political discussions as a categorical response variable, to determine the association of political discussions on Facebook. Results of a multivariate logistic regression model with both age and gender as the categorical predictors are presented in Table 8. Both gender and age were non-significant for the political discussions. The p-values for the significance of coefficients are very large indicating that political discussions on Facebook for males as compared to females and for age group 2 as compared to age group 1 are not significant, similar finding as from $\chi^{2}$.

Table 8: Regression model for factors influencing political

\begin{tabular}{cccc}
\multicolumn{4}{c}{ discussions on Facebook } \\
\hline & Estimate & $\mathrm{z}$ value & $\mathrm{p}$-value \\
\cline { 2 - 4 } (Intercept) & 1.19344 & 3.170 & 0.00152 \\
Gender (M) & -0.03223 & -0.076 & 0.93928 \\
Age 2 (22-30) & -0.36420 & -0.965 & 0.33464 \\
\hline
\end{tabular}

Consequently, this study proved that both gender and age were not significant variables in political discussions on Facebook, indicating that there are no gender differences among students in Jordan when it comes to the political discussions.

To determine whether Facebook has been used as an aid for peers learning (Q4), users were asked if they discuss what they learned in a classroom on a Facebook forum. Out of 161 answered questions, $17 \%$ of the respondents answered for always, 58\% answered for sometimes, and $27 \%$ answered for never. This result shows that more than $80 \%$ of the Facebook users used Facebook for peers learning purpose. This is similar to the findings by Eren (2012).

While most people probably think the dramatic increase of Facebook users only occur in Englishspeaking countries, when the subject of a language used comes up, English language is not merely a barrier in using the Facebook. This study has revealed that Facebook users in Jordan (Arabic speaking country) opt to use the English language more than Arabic, with the majority of respondents (64\% of Facebook users) use the English language to display Facebook, while the Arabic language was the choice of language for only $36 \%$ of respondents (Q9). 


\section{Conclusion}

This study had been conducted to investigate behaviors of Facebook users who are also undergraduate students in Jordan. The finding shows that nearly $90 \%$ of students have a Facebook account. Facebook has been used as a medium for sharing personal information, discussing political issues, and peers learning. The results of the study also suggest Arabic male students are more daring than female students in "publicizing" themselves online. The local culture may influence the behavior of female users when they appear online. However, the study proved that there are no gender differences among students when it comes to the interest in political discussions.

Furthermore, the findings of this study indicate, "friends" is the main factor of having a Facebook account. This is similar to the findings by Shen and Khalifa (2010) and Al-Sharqi et al. (2015). Consequently, we can conclude that the main reason for students in the Arab world to have a Facebook account is to stay connected and chat with their friends.

\section{Acknowledgement}

We thank Faculty of Science and Information Technology at Zarqa University, for allowing us to conduct the survey of this research in the Academic Year 2011/2012. We also thank students of the Faculty for participating in this survey and Dr. Shaheena Bashir for helping us with the statistical analysis.

\section{References}

Ahn J (2011). The effect of social network sites on adolescents' social and academic development: Current theories and controversies. Journal of the American Society for Information Science and Technology, 62(8): 1435-1445.

Akour I, Alshare K, Miller D, and Dwairi M (2006). An exploratory analysis of culture, perceived ease of use, perceived usefulness, and internet acceptance: The case of Jordan. Journal of Internet Commerce, 5(3): 83-108.
Al-Sharqi L, Hashim K, and Kutbi L (2015). Perceptions of social media impact on students' social behavior: A comparison between Arts and Science students. International Journal of Education and Social Science, 2(4): 122-131.

Aydin S (2012). A review of research on Facebook as an educational environment. Educational Technology Research and Development, 60(6): 1093-1106.

Benson V, Filippaios F, and Morgan S (2010). Online social networks. International Journal e-Business Management, 4(1): 20-33.

Bsharah M, Gasaymeh AM, and Abdelrahman MB (2014). The Relationship between the use of Social Networking Sites (SNS) and perceived level of social intelligence among Jordanian university students: The case of Facebook. International Journal of Psychological Studies, 6(3): 1-12.

Eren Ö (2012). Students' attitudes towards using social networking in foreign language classes: A Facebook example. International Journal of Business and Social Science, 3(20): 288-294.

Hargittai E (2007). Whose space? Differences among users and non-users of social network sites. Journal of ComputerMediated Communication, 13(1): 276-297.

Hull G, Lipford HR, and Latulipe C (2011). Contextual gaps: privacy issues on Facebook. Ethics and Information Technology, 13(4): 289-302.

Karpinski AC and Duberstein A (2009). A description of Facebook use and academic performance among undergraduate and graduate students. In the American Educational Research Association Annual Meeting, San Diego, USA.

Pempek TA, Yermolayeva Y, and Calvert SL (2009). College students' social networking experiences on Facebook. Journal of Applied Developmental Psychology, 30(3): 227-238.

Rouis S, Limayan M, and Salehi-Sangari E (2011). Impact of Facebook usage on students' academic achievement: Roles of self-regulation and trust. Electronic Journal of Research in Educational Psychology, 9(3): 1696-2095.

Shen K and Khalifa M (2010). Facebook usage among Arabic college students: Preliminary findings on gender differences. International Journal of E-Business Management, 4(1): 53-65.

Vrocharidou A and Efthymio I (2012). Computer mediated communication for social and academic purposes: Profiles of use and university students' gratifications. Computers and Education, 58(1): 609-616.

Yaseen SG and Al Omoush KS (2012). Toward developing a model of Facebook adoption among Arab people. Humanities and Social Sciences Review, 1(2): 69-76. 